\title{
A multi-ontology view of ergonomics: applying the Cynefin Framework to improve theory and practice
}

\author{
Wendy Elford $\mathrm{a}^{*}$ \\ ${ }^{a}$ Now to Next Pty Ltd, PO Box 235 Mawson, ACT 2607, Australia
}

\begin{abstract}
Ergonomics literature has often identified concerns about the difficulty of gaining support for ergonomics interventions. There appears to be a shift from the view that ergonomics issues can be made to be simple, towards a wider appreciation of the complexity of ergonomics problems in the real world. A framework from knowledge management - the Cynefin Framework - is recommended as providing a way of re-perceiving situations where ergonomics problems may be present or have already been identified. The framework uses multiple ontologies and indicates appropriate courses of investigation and action for each of four domains - the simple, the complex, the complicated and the chaotic. This paper presents evidence of the need for a multi-ontology approach and shows how the Cynefin Framework can be applied to ergonomics.
\end{abstract}

Keywords: Complex, complicated, system, interdisciplinary

\section{Background}

Ontology can simply be defined as 'a particular theory about the nature of being or the kinds of things that have existence' [22]. A practical application of ontology, ontological perspectivalism, 'accepts that there are alternative views of reality, and that this same reality can be represented in different ways. The same section of the world can be observed through a telescope, with the naked eye, or through a microscope'[23]. Multiple ontological perspectives within ergonomics are seen in discussions about the future of ergonomics [33,2,3], in new areas of application [9] but most importantly, in the way issues are 'framed' in ergonomics literature. It is now a century since Frederick W. Taylor's book Scientific management was published [17]. Views of work have shifted. From the mid-1980's macro-ergonomics [9.19] and micro-ergonomics and have co-existed with a systems approach to ergonomics with variable results [14,22]. Kleiner, for example, sees a macroergonomic approach as moving beyond the design of the interface between humans and the larger system
[19] as 'technology and systems interact and they do so within an organizational context. Organizations operate within larger environmental systems and therefore it behooves the ergonomist to know enough about the larger system factors so that their ergonomics success can be maximized' [19 p83]. Macroergonomics integrates 'principles and perspectives from industrial, work and organizational psychology' [19 p83], however even this approach limits the variety of perspectives from which ergonomics issues can be understood.

More recently, there is evidence of a shift towards using the concept of open systems, soft systems methodology, complexity and complex adaptive systems as a means of understanding and acting on complex issues in domains such as environmental science. This is now occurring in ergonomics [4, 33]. As many of the interests in other domains also intersect with ergonomics, the frameworks and ontologies used to investigate these issues should move beyond those centred on ergonomics. Using this approach, complex interactions, for example between the drive for a lower carbon footprint, new building codes and

*Corresponding author. E-mail: info@ergodesign.com.au 
a wider spacing between luminaires in an office might anticipate the ergonomics issues related to lower illumination and an ageing workforce. One useful approach to improve the exploration of complex ergonomics issues is to consider the large sector of literature and research which already exists within ergonomics - cognitive ergonomics. In this way, ergonomists can reconsider the nature of thinking and reasoning processes applied to look into ergonomics issues and consider them within a broader context.

In the same way that macro-ergonomics aims to consider ergonomics in the natural setting, macrocognition describes cognitive functions performed in the natural setting [18]. As these 'natural settings' [18 p81] can be perceived multiple ways, a multiontology approach seems appropriate. Hollnagel's extensive work in cognition, decision support and human errors has been applied in the real world. Ergonomists who use different ontologies - who explore different ways of seeing ergonomics problems are actively using macrocognition.

Macrocognition [18] is a term describing 'the mental activities that must be successfully accomplished to perform a task or achieve a goal. Other somewhat related terms have been used in this regard, such as situated cognition and extended cognition.

Several areas of research are now starting to intersect. The concepts of macrocognition and complexity have been explored in human factors and ergonomics (HFE) in greater depth in literature on situational awareness [22,34,35] and like the authors of these papers, other authors such as Gary Wong [28], Csontos [5] and Elford [8] have recognised the potential application of an ontological framework called the Cynefin Framework within domains of HFE and occupational health and safety OHS. This paper aims to create a bridge between the work done by Sardone and Wong [28] and Walker and Stanton [33] on understanding emergence and complexity in ergonomics and the work of Dave Snowden on emergence and complexity by relating published examples of ergonomics research to the Cynefin Framework.

\section{A classification of types of emergence and introduction to the Cynefin Framework}

Emergence can be defined as 'coming into view or notice' [7 p617]; the implication for ergonomics research is that a concept or issue has been concealed and there is a point where it 'emerges' into current thinking. A description of types of emergence serves as an introduction to the Cynefin Framework.

\subsection{Types of emergence}

In their comprehensive paper on complexity, Walker et al. provide a classification system with the attribute of emergence given in four levels. Walker et al define emergence as 'the behavior that arises as systems operate in the transition region between stability and chaos [33 p1181]. An alternative definition describes the transition being between order and disorder. Walker et al. provide four definitions from Bar-Yam [33 p1181]. These are included in Table 1. With Type 0, emergence is considered to be absent, that is, it is relatively easy to diagnose a systems' collective behavior. Types 1 and 2 include progressively greater knowledge of the positions and dynamics of agents within the system, Type 2 having greater knowledge of possible states of the system. The fourth type, Type 3, is considered to have strong emergence and additional knowledge of the environment the system fits within.

Table 1 Description of four different types of emergence as developed by Walker et al [33] from Bar-Yam [33 p1181]

\begin{tabular}{|c|c|c|}
\hline Emergence & Type & $\begin{array}{l}\text { Information needed in order to make a diagnosis of the system's collective } \\
\text { behaviours. }\end{array}$ \\
\hline None & Type 0 & $\begin{array}{l}\text { Deterministic: Knowledge of individual system components sufficient to fully } \\
\text { explain global system behavior. }\end{array}$ \\
\hline Weak & Type 1 & $\begin{array}{l}\text { As for type } 0 \text { but with additional knowledge about the positions and dynamics } \\
\text { of individual entities in a system, this being sufficient to describe the } \\
\text { 'microscopic' as well as 'macroscopic' parts of the system. }\end{array}$ \\
\hline Strong & Type 2 & $\begin{array}{l}\text { As for type } 1 \text { but with additonal knowledge of possible states and } \\
\text { configurations the system can adopt. }\end{array}$ \\
\hline Strong & Type 3 & $\begin{array}{l}\text { As for type } 2 \text { but with additional knowledge of the environment that the } \\
\text { system resides in. }\end{array}$ \\
\hline
\end{tabular}


Another way of viewing this rating scheme is that emergence, an attribute of the system under consideration, occurs either weakly or not at all for Types 0 and 1 , and more strongly for Types 2 and 3 . While this schema emphasizes the importance of valuing emergence as an attribute, unfortunately it does not assist the researcher to identify emergent concepts or issues. Macrocognition links ergonomics problem solving with evolving practice in knowledge management.

\section{Cynefin Framework}

Dave Snowden developed his early versions of the the Cynefin Framework whilst working at IBM. [30]. This framework provides an innovative way to look at ergonomics issues using the idea of 'ontological perspectivalism' introduced earlier in this paper. The Cynefin Framework considers two basic types of 'ontologies' - the ordered and the unordered and a third one of disorder. The ordered ontologies are described as the simple and the complicated domains, the unordered ontologies as the complex and chaotic domains. Each has different qualities with respect to cause - effect relationships, and for each domain there is a different approach for making sense of a situation. The concept of emergence appears most strongly in the complex domain, but the descriptions given by Snowden suggest that it is also present, though more weakly, in the complicated domain. The qualities of each of these domains are described in Figure 1.

\subsection{Domains of Cynefin Framework}

\subsubsection{Simple domain}

In this domain, cause and effect are known. Issues in this domain relate well to a deterministic approach where prediction is feasible and outcomes can be engineered given specified inputs.

\subsubsection{Complicated domain}

This is the domain of the expert. Given sufficient time and resources, a system or interacting systems and their elements can be defined. Once known, the interrelationships are considered relatively stable.

\subsubsection{Chaotic domain}

In this domain, the system is in turbulence and there is no perceivable evidence of cause and effect. The emphasis in this domain is not on investigation, but on action that allows some sense to be made of the chaos which in turn creates just enough stability to allow the next action.

\subsubsection{Complex domain}

In the complex domain, the interaction of many agents makes it impossible to apply standard analytic techniques. It is possible to make sense of the situation through finding patterns in the interactions between the agents, however cause and effect can only be seen after the fact. The focus is on sensing these patterns through the use of probes, and managing the changing patterns over time.

\subsection{Application of Cynefin Framework}

There appears to be huge potential for the use of the Cynefin Framework for reframing diverse issues within disciplines such as information systems which, like ergonomics, are characterized by significant change and diversity [10].

Cynefin is much more than a simple categorization framework. Snowden has demonstrated how the framework can be used to identify interventions that shift the position of an issue between domains on the framework to tackle what are often known as 'wicked problems.'

Kurtz and Snowden [20] propose a range of interventions which can be applied to an issue to shift it between different domains. These include activities such as 'just in time transfer' and 'imposition' which act to shift an issue between the complex and complicated domains and the chaotic and simple domains respectively. The potential for the Cynefin Framework and these specific types of interventions to be applied to occupational health and safety has been demonstrated by Sardone and Wong [28]. The following sections provide some examples of how the Cynefin framework can start to be applied within ergonomics.

\subsubsection{Application to ergonomics Example 1: OHS}

This first selection of papers locates examples of ergonomics and safety research with respect to the Cynefin Framework.

Two of the initial papers considered here appear to question the efficacy of a systems approach to safety. 


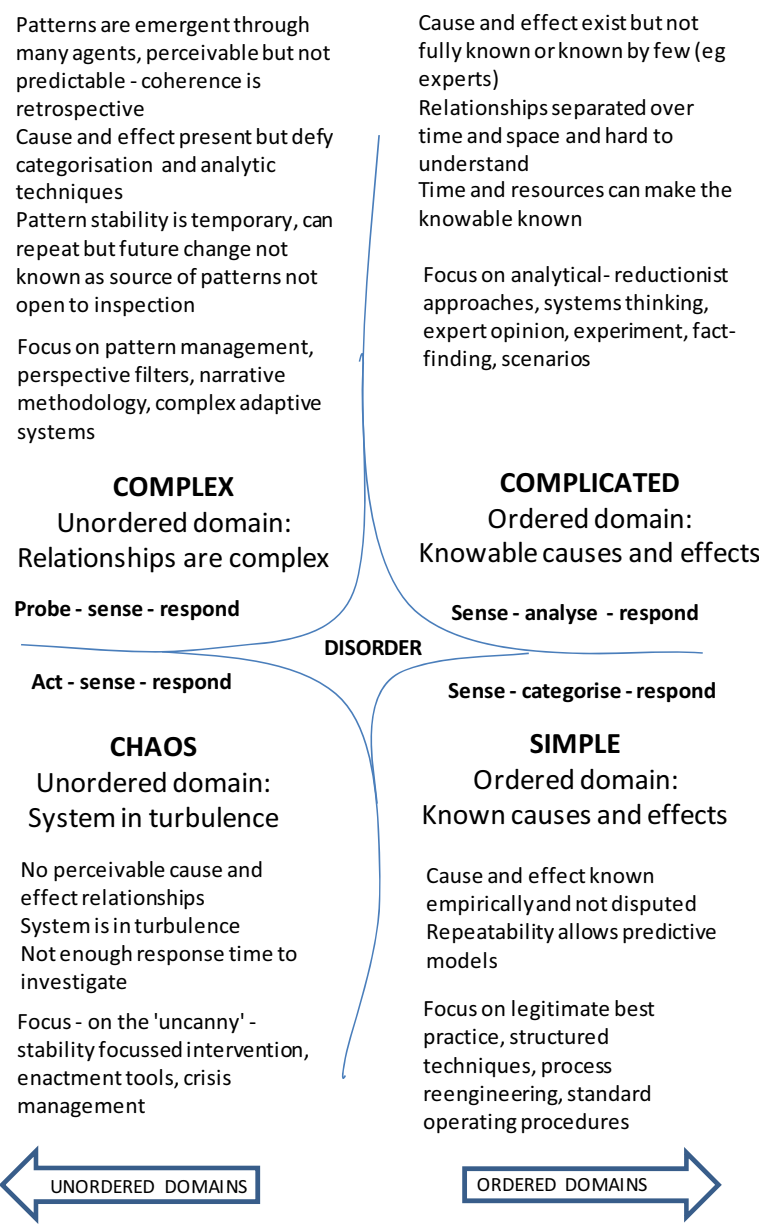

Figure 1

The Cynefin framework, created by Dave Snowden [19 pp468-470]

Hollagnel with his paper entitled 'Risk + barriers = safety?' considers barriers, concluding that these are insufficient to guarantee safety [15]. A second paper entitled 'How good micro/macro ergonomics may improve resilience, but not necessarily safety' [22] considers the importance of the financial performance of the system as well as the legal pressures exerted on the system. Both papers locate OHS in the complex domain.

In a paper entitled 'Avoiding health and safety risks, Csontos showcases some of the features of OHS which demonstrates it as being in the complex domain, suggesting that the Cynefin Framework has a potentially useful role to play in managing $\mathrm{OHS}$ [5].

A more analytical approach is taken by Lars [21] who considers barriers from the perspective of a safety system, a contribution which can be placed in the complicated domain. Finally, an example of a paper which would be placed in the simple domain 'An evaluation of guardrail systems for preventing falls through roof and floor holes' [1] looks at much more specific factors in injury prevention.

The use of the framework can be demonstrated in a research project using proprietary software developed by Snowden [18]. In a highly relevant paper, Sardone and Wong [28], actually apply the Cynefin framework, using software for a novel survey method called Sensemaker [6] developed by Snowden.

In this paper, Sardone and Wong demonstrate firstly how safety and health issues can be mapped onto the framework and secondly, how they could be addressed using some of the tactics put forward by Kurtz and Snowden as being able to shift issues between domains.

\section{Example 2: Office ergonomics}

In this example, papers which describe the ergonomics of the design of the office, office work and the productivity of office workers are considered. 
Two papers which discuss this topic from the perspective of complexity focus on office design and office productivity. Price explores the idea of 'The complex adaptive workplace: A theoretical link between office design and productivity' [24]. In a paper entitled 'Office productivity: a shift from cost reduction to human contribution' Haynes compares two different paradigms, one of control and which considers how office workers might be enabled to improve productivity [25]. Both papers consider the interaction of a broad range of factors relevant to office ergonomics. And as Price states, take a complexity perspective.

In another paper authored by both Haynes and Price, these researchers attempt to quantify relationships between design and the interaction of workers in the office environment. This paper is entitled 'Quantifying the complex adaptive workplace' [13]. It takes a more analytical approach, testing specific hypotheses. This paper is an example of an approach which might be placed in the complicated domain. Another more specific approach which can be placed in the complicated domain but located closer to the simple domain is presented in Robertson et al.'s contribution on 'Flexible workspace design and ergonomics training: Impacts on the psychosocial work environment, musculoskeletal health, and work effectiveness among knowledge workers' [26]. This paper sets out to formalize the relationship between two major factors and three outcome measures, looking for cause-effect relationships and seeking to simplify the system under consideration.

An example of a paper describing a related ergonomics issue in office work, again by one of the same authors, considers the 'Impact of seating posture on user comfort and typing performance for people with chronic low back pain'[30]. Each of the factors considered in this very specific approach to personal productivity might be represented in one of the previous papers; here the authors aim to reduce the relationships to relatively simple set of conclusions that apply to a very specific group.

As for the OHS example, there are limited but valuable applications of this framework within ergonomics. Elford [8] describes the relevance of the Cynefin Framework to understanding emerging issues within the ergonomics of office wear. In a pilot study within a large public sector agency, Sensemaker [6] was used to collect narrative data seeking worker's views on the future of office work. The author concludes that the use of the framework and software tool provide an important and valid approach to in- vestigating a complex issue - emerging issues in the ergonomics of office work.

\section{Discussion and conclusion}

Of the authors whose work is presented above, three have made specific mention in their body of work of the value of taking a complexity and specifically a multi-ontology approach [28,25,8]. Like Walker et al. [33], they identify a need to take an approach which supports action, not just the classification of a situation in terms of the degree of complexity. While the Cynefin Framework has not yet been used extensively within ergonomics, there is early evidence that it will provide a valid and effective means of linking the research associated with an ergonomics problem with practical steps for action. This is achieved because the framework provides not only a multi-ontology approach, but recommends for each domain, how to approach problems in that sector. While not described in detail here, Sardone and Wong [18] and Elford [20] argue that this framework not only has explanatory power, but that it also shows how the initial investigatory approach or prehypothesis research as Snowden calls it can point to appropriate actions, In this way, complex issues 'wicked problems' - can be dealt with more effectively by a targeted approach which also has built in metrics. A second and very important point is that a multi-ontology and in particular, a complexity approach supports valuable research in the real world as it allows for not only multiple views, but the interaction of multiple agents.

Snowden describes in great detail the theoretical underpinnings of his approach [20,30,31] and how specifically developed software can allow both qualitative and quantitative assessments of a complex situation. The benefit of testing the application of this approach within ergonomics is that issues that were previously too complex to understand can now be considered for research. As ergonomics is increasingly operating in a complex environment and working more closely with other disciplines, having a theoretical and practical approaches to current, complex ergonomics and interdisciplinary problems holds the promise of more effective practice in ergonomics into the future. 


\section{References}

[1] T. G. Bobick, E. A. McKenzie Jr and T.-Y. Kau, Evaluation of guardrail systems for preventing falls through roof and floor holes, Journal of Safety Research 41(3)(2010), 203-211.

[2] J. D. Brewer and S. M. Hsiang, The 'ergonomics paradigm: foundations, challenges and future directions, Theoretical Issues in Ergonomics Science 3(3)(2002), 285-283-285.

[3] O. Brown, Editorial XIV Triennial Congress of the International Ergonomics Association and 44th Annual Meeting of the Human Factors and Ergonomics Society: Ergonomics for the new millennium, Ergonomics 43(7)(2000), 829-832.

[4] P. Carayon, Human factors of complex sociotechnical systems, Applied Ergonomics 37(4)(2006), 525-535.

[5] A. Csontos, Avoiding health and safety issues: keeping the focus on innovation, Viewpoint (n.d.), http://www.deloitte.com/assets/Dcom-

Australia/Local\%20Assets/Documents/Services/Risk\%20servi ces/Corporate\%20responsibility/OHS_article_Andi_Csontos.p df.

[6] Cognitive Edge. Sensemaker. Sensemaker Suite. 2.2 beta 1 edn: Cognitive Edge Pte Ltd; 2006-2009.

[7] A. Delbridge, J. R. L. Bernard, D. Blair, S. Butler, P. Peters and Y. C. The Macquarie Dictionary Federation Edition A-L. In: J. B. A Delbridge, D Blair, S Butler, P Peters, C Yallop, editor. The Macquarie Library. Third edn. Sydney: Macquarie Library Pty Ltd; 1997a.

[8] W. Elford. Emerging Issues in ergonomics: a methodological framework for foresight and sensemaking, $\mathrm{PhD}$ Dissertation, University of Canberra, 2011.

[9] W. D. Elford and W. S. Green. Future issues in ergonomics: cost-benefit analysis and organisational planning. In: R. Pikaar, E. Koningsveld and P. Settels, editors. Meeting diversity in ergonomics - Proceedings of the IEA 2006 Congress Mastricht, Netherlands: International Ergonomics Association; 2006. p. abs. 0147.

[10] H. Hasan and A. Kazlauskas, Making sense of IS with the Cynefin Framework, (2009), http://www.pacisnet.org/file/2009/[31]Making\%20Sense \%20of\%20IS\%20with $\% 20$ the $\% 20$ Cynefin $\% 20$ Framework.pdf.

[11] S. Haynes and K. Williams, Impact of seating posture on user comfort and typing performance for people with chronic low back pain, International Journal of Industrial Ergonomics 38(1)(2008), 35-46.

[12] B. P. Haynes, Office productivity: a shift from cost reduction to human contribution, Facilities 25(11/12)(2007), 452-462.

[13] B. P. Haynes and I. Price, Quantifying the complex adaptive workplace, Facilities 22(1/2)(2004), 8-18

[14]H. W. Hendrick, Applying ergonomics to systems: Some documented "lessons learned", Applied Ergonomics 39(4)(2008), 418-426.

[15] E. Hollnagel, Risk + barriers = safety? Safety Science 46(2008), 221-229.

[16] A. S. Imada and P. Carayon, Editors' comments on this special issue devoted to macroergonomics, Applied Ergonomics 39(4)(2008), 415-417.

[17] R. Kanigel, The one best way : Frederick Winslow Taylor and the enigma of efficiency. New York: Viking, 1997.

[18] G. Klein, K. G. Ross, B. Moon, K. D. E, R. Hoffman and E. Hollnagel, Macrocognition, IEEE Computer Society (2003), 18(3)(2003), 81-85

[19] B. M. Kleiner, Macroergonomics: Analysis and design of work systems, Applied Ergonomics 37(1)(2006), 81-89.
[20] C. F. Kurtz and D. J. Snowden, The new dynamics of strategy: sense-making in a complex and complicated world, (2003), http://xenia.media.mit.edu/ brooks/storybiz/kurtz.pdf.

[21] H.-R. Lars, Analysis of safety functions and barriers in accidents, Safety Science 47(3)(2009), 353-363.

[22] G. Morel, R. Amalberti and C. Chauvin, How good micro/macro ergonomics may improve resilience, but not necessarily safety, Safety Science 47(2)(2009), 285-294.

[23] Ontology, (Access date 30 Sept 2011 from http://www.merriam-webster.com/dictionary/ontology.

[24] I. Price, Complexity, complicatedness and complexity: a new science behind organizational intervention?, Emergence: Complexity \& Organization, An International Transdisciplinary Journal of Complex Social Systems 6(1-2)(2004), 40-48.

[25] I. Price, The complex adaptive workplace: a theoretical link between office design and productivity? Sheffield Hallam University, united Kingdom http://www.ifm.eng.cam.ac.uk/mcn/pdf_files/part5_4.pdf http://www-mmd.eng.cam.ac.uk/mcn/pdf files/part5 4.pdf.

[26] M. M. Robertson, Y.-H. Huang, M. J. O'Neill and L. M. Schleifer, Flexible workspace design and ergonomics training: Impacts on the psychosocial work environment, musculoskeletal health, and work effectiveness among knowledge workers, Applied Ergonomics 39(4)(2008), 482-494.

[27] P. M. Salmon, N. A. Stanton, G. H. Walker, C. Baber, D. P. Jenkins, R. McMaster and M. S. Young, What really is going on? Review of situation awareness models for individuals and teams, Theoretical issues in ergonomics science 9(4)(2008), 297-323.

[28] G. Sardone and G. Wong. Making sense of safety: a complexity-based approach to safety interventions. Asso-ciation of Canadian Ergonomists 41st Annual conference. Kelowna, BC: Association of Canadian Ergonomists; 2010.

[29] B. Smith and B. Klagges. Philosophy and biomedical information systems. In: K. Munn and B. Smith, editors. Applied ontology: an introduction. Ontos Verlag: Frankfurt ; New Brunswick; 2008.

[30] D. Snowden. Naturalising sense making. Brisbane; 2007.

[31] D. J. Snowden, Cynefin sensemaking framework, Wikidot (2010b), Retrieved from http://paei.wikidot.com/snowden-d-jcynefin-sensemaking-framework.

[32] N. Stanton and R. Stammers, Bartlett and the future of ergonomics, Ergonomics 51(1)(2008), 1-13.

[33] G. H. Walker, N. A. Stanton, P. M. Salmon, D. P. Jenkins and L. Rafferty, Translating concepts of complexity to the field of ergonomics, Ergonomics 53(10)(2010), 1175-1186.

[34] G. H. Walker, N. A. Stanton, P. M. Salmon and D. P. Jenkins, A review of sociotechnical systems theory: a classic concept for new command and control paradigms, Theoretical issues in ergonomics science 9(6)(2008), 479-499.

[35] G. H. Walker, N. A. Stanton, R. Stewart, D. Jenkins, L. Wells, P. Salmon and C. Baber, Using an integrated methods approach to analyse the emergent properties of military command and control, Applied Ergonomics 40(4)(2009), 636-647. 